\title{
Study on the Use of Evolved Gas Analysis FT-IR (EGA FT-IR) for the Evaluation of Cheese Volatile Fraction
}

\author{
Milena Povolo*,a, Giovanni Cabassi ${ }^{\mathrm{a}}$, Mauro Profaizer ${ }^{\mathrm{b}}$ and Silvia Lanteri ${ }^{\mathrm{c}}$ \\ ${ }^{a}$ CRA - Centro di Ricerca per le Produzioni Foraggere e Lattiero-casearie, via A. Lombardo 11, 26900 Lodi, Italy \\ ${ }^{b}$ Dipartimento di Ingegneria Idraulica, Ambientale, Infrastrutture Viarie, Rilevamento, Politecnico di Milano, piazza \\ Leonardo da Vinci 32, 20133 Milano, Italy \\ ${ }^{c}$ Dipartimento di Chimica e Tecnologie Farmaceutiche e Alimentari, Università di Genova, via Brigata Salerno, 16147 \\ Genova, Italy
}

\begin{abstract}
The analysis of volatile compounds for food products characterization is currently performed by gas chromatographic separation, often coupled with mass spectrometry. In our research the possibility of the application of the Fourier-transform infrared spectroscopy (FT-IR) technique to the cheese volatile fraction evaluation was investigated. An Evolved Gas Analysis (EGA) FT-IR prototype, developed to detect some volatile molecules released from bottle grade PET, was used. The preliminary step of the work was devoted to the set up of the best analytical conditions and instrumental parameters for cheese analysis. Thirty nine samples of PDO Bitto cheeses were analysed by both EGA FT-IR and Solid Phase Microextraction/Gaschromatography/Mass Spectrometry (SPME/GC/MS) technique. Satisfactory correlations were observed between the FT-IR spectra and the most abundant compounds detected by SPME/GC/MS. Even though some aspects of the analytical conditions need to be improved, the results obtained are promising for a possible application of EGA FT-IR in the evaluation of volatile fraction of foods.
\end{abstract}

Keywords: EGA FT-IR, SPME/GC/MS, volatile fraction.

\section{INTRODUCTION}

Flavour is one of the main characteristics that determine dairy products quality. Among the different techniques applied for the study of volatile compounds composition, the most used are based on the gas chromatographic separation of the substances extracted, often coupled with the mass spectrometry detection [1]. Volatile fraction analysis is one of the most important methods in quality evaluation of food and it has been widely applied for this scope. Flavour composition of dairy products has been evaluated in several studies and, in particular, cheese volatiles have been widely analyzed with different scopes, such as to study the effects of the ripening process [2-3], animal feeding [4-6], origin of defects [7], and influence of milk protein genetic variants [8]. Among the different techniques available for the evaluation of volatiles, those able to provide the result in a very short time are very appealing. In fact, one of the objectives of the method development is the possibility to set up an analytical approach rapid and applicable also for the on-line monitoring of the food quality. With this scope the instrumentations like those belonging to the category of "Electronic Noses", have been proposed and tested [9-10].

The Infrared (IR) Spectroscopy techniques are an interesting field of study for the development of rapid methods. Infrared spectroscopy is based on the vibrations of the atoms of a molecule. An infrared spectrum is usually obtained by

*Address correspondence to this author at the CRA - Centro di Ricerca per le Produzioni Foraggere e Lattiero-casearie, via A. Lombardo 11, 26900 Lodi, Italy; Tel: +39 0371 45011; Fax: +39 0371 35579;

E-mail: milena.povolo@entecra.it passing infrared radiation through a sample and determining what fraction of the incident radiation is absorbed at a particular energy. Fourier-transform infrared (FT-IR) spectroscopy consists in the following principle: radiation containing all IR wavelengths (e.g. 5000-400 $\mathrm{cm}^{-1}$ ) is split into two beams, of which one is of fixed length, whereas the other is of variable length (movable mirror). The varying distances between two pathlengths result in an interferogram, a sequence of constructive and destructive interferences and hence variations in intensities. Fourier transformation, which is a mathematical operation, converts this interferogram from the time domain into an amplitude (spectrum), that is a function of frequency.

FT-IR on condensed phase is currently applied for the determination of both major (i.e. total fat, proteins, lactose) and some minor (i.e. citric acid, free fatty acids) constituents of dairy products [11]. The instrumentations with this type of detection allow the performance of the determinations in a very short time and for this reason, especially regarding milk quality control, they are currently adopted in the routine analyses [12]. As far as the detection of molecules in gas phase is concerned, FT-IR could be coupled to a gas chromatograph, being a universal, selective and specific detector, even if it has low sensitivity [13]. Moreover it could be combined with a thermo-analytical instrument. The latter approach belongs to the so called Evolved Gas Analysis (EGA), defined by IUPAC Compendium of chemical terminology as "a technique in which the nature and/or amount of volatile product/s released by a substance subjected to a controlled temperature is (are) determined". The thermoanalytical instrument is coupled with a FT-IR spectrometer 
by means of a heated transfer line; the released vapors or gases are transferred to the heated gas cell of the FT-IR instrument [14]. The principal applications of EGA FT-IR have been in the determination of thermal reaction behaviour and decomposition mechanism of polymers; in addition it has been used in the assessment of fossil fuels for energy production and then in the pharmaceutical industry for residual solvent determination, drug composition and shelf life monitoring [15-16]. Other applications are the real-time identification and monitoring of vapors or gases evolved from certain combustion processes, such as those resulting from thermal breakdown experiments in controlled environments, pyrolysis vapors, fire gases from direct burning of rubber or plastics [17]. As regards the food analysis, EGA FT-IR has been applied on spaghetti pasta and hazelnuts to study the effects of some technological processes by monitoring the evolution of water or carbon dioxide [16-18].

To our knowledge, at the moment, no studies are present in literature on the use of this technique to headspace analysis of volatiles extracted from food matrices. In this research the use of the EGA FT-IR to study cheese volatile compounds was investigated. The volatile fraction of Bitto, a Protected Designation of Origin (PDO) cheese, produced only between June 1st and September 30th in the Alpine area of Valtellina (Lombardia region, Italy) was evaluated. The aim of this study was to verify if EGA FT-IR analysis could represent a new approach for the evaluation of cheese volatile composition.

\section{MATERIALS AND METHODOLOGY}

\subsection{Materials}

Thirty nine samples of three months ripened Bitto PDO cheese were collected from local dairy farmers, the maturing of all the sampled cheeses was 70-85 days. Cheese slices were stored at $-20^{\circ} \mathrm{C}$ until the analyses and then finely homogenised before sampling.

Authentic standards of hexanoic acid, ethanol, acetaldehyde (Sigma-Aldrich, Milan, Italy) were analysed for the spectra recognition by EGA FT-IR. Anhydrous sodium sulphate (Sigma-Aldrich, Milan, Italy) was used in sample preparation for the EGA FT-IR determination.

\subsection{Chemical Composition}

Cheese samples were analysed regarding their chemical composition, by applying the following methods: total solids [19], fat [20], ash [21], total protein [22]. Each analysis was performed in duplicate.

\subsection{Solid Phase Microextraction/Gaschromatography/ Mass Spectrometry (SPME/GC/MS) Analysis}

A divinylbenzene/carboxen/polydimethylsiloxane, 50/30 $\mu \mathrm{m}, 2-\mathrm{cm}$-long fiber was used to collect volatile fractions by SPME. Four grams of grated cheese were weighed in a 20$\mathrm{ml}$ crimp-top vial, and sealed with an aluminum cap provided with a pierceable septum $(23 \times 75 \mathrm{~mm}$, Varian, Palo Alto, CA). Sample was allowed to equilibrate to $40^{\circ} \mathrm{C}$ in a thermostatic bath for $5 \mathrm{~min}$ and the fiber was exposed to the headspace for $30 \mathrm{~min}$. GC/MS conditions were those reported by Povolo et al. [23]. The identification of volatile compounds was performed by comparison with both the mass spectra of the Wiley library [24] and authentic stan- dards analysed under the same GC/MS conditions. Values were expressed as area units/100000.

\subsection{EGA FT-IR Analysis}

The device used for this research was a prototype, developed to detect volatile molecules released from bottle grade PET (Fig. 1). It consisted of a FT-IR spectrometer equipped with a Deuterated Triglycine Sulfate (DTGS) detector, a multiple-pass long path absorption cell, a thermal desorption unit and a Tenax TA 60/80 trap (Perkin Elmer, Wallasley, MA, USA). Dynamic headspace under nitrogen flow (high grade purity), followed by concentration in the Tenax trap, was used for the extraction of the volatile compounds. A thermal imaging camera CYCLOPS TI35 (Land Instruments International LTD, Dronfield, UK) was used to monitor the temperature inside the thermal desorber and the sample.

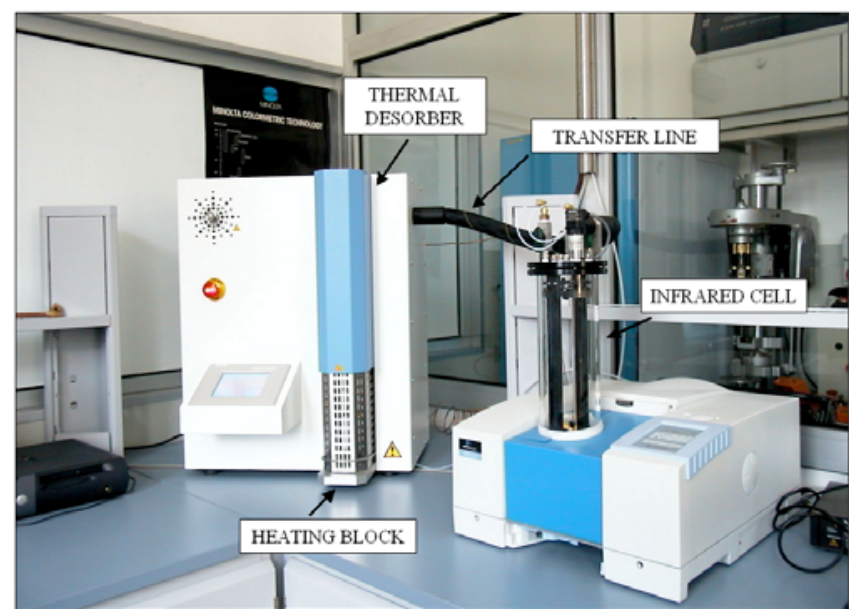

Fig. (1). Prototype of EGA FT-IR analyzer used for the research.

Four grams of cheese were weighed, mixed with $10.5 \mathrm{~g}$ of anhydrous sodium sulphate and shaped into five spheres, all having the same diameter. Anhydrous sodium sulphate was used in order to retain water and prevent the humidity from reaching the IR detector. The spheres were placed, on an aluminium foil, in the special chamber within the oven of the desorption unit. The sample was heated up to $40^{\circ} \mathrm{C}$ under nitrogen flow for 30 minutes for the extraction of the volatile molecules and their adsorption on the Tenax trap. Afterwards the trap was heated at $230^{\circ} \mathrm{C}$ to release the volatiles and transfer them, through the transfer line heated at $60^{\circ} \mathrm{C}$, to the infrared cell. The IR cell was a $60 \mathrm{~cm}$ cylinder, provided with a mirror system at multiple reflection, that extends the optical pathlength up to $14 \mathrm{~m}$. Spectra were recorded in the range of $4000-450 \mathrm{~cm}^{-1}$ at resolution of $4 \mathrm{~cm}^{-1}$.

\subsection{Statistical Evaluation}

The correlation between data obtained from SPME/GC/MS and EGA FT-IR analyses was evaluated by applying V-PARVUS package (University of Genova, Italy) for chemometric techniques of variable selection and multivariate regression [26].

\section{RESULTS AND DISCUSSION}

Cheese samples were characterized with regard to their chemical composition. Bitto PDO cheese is produced from whole raw milk of cows grazing on pasture, only during the 
Table 1. Volatile Compounds of Bitto PDO Cheese Detected by SPME/GC/MS Technique (Area Values/100000)

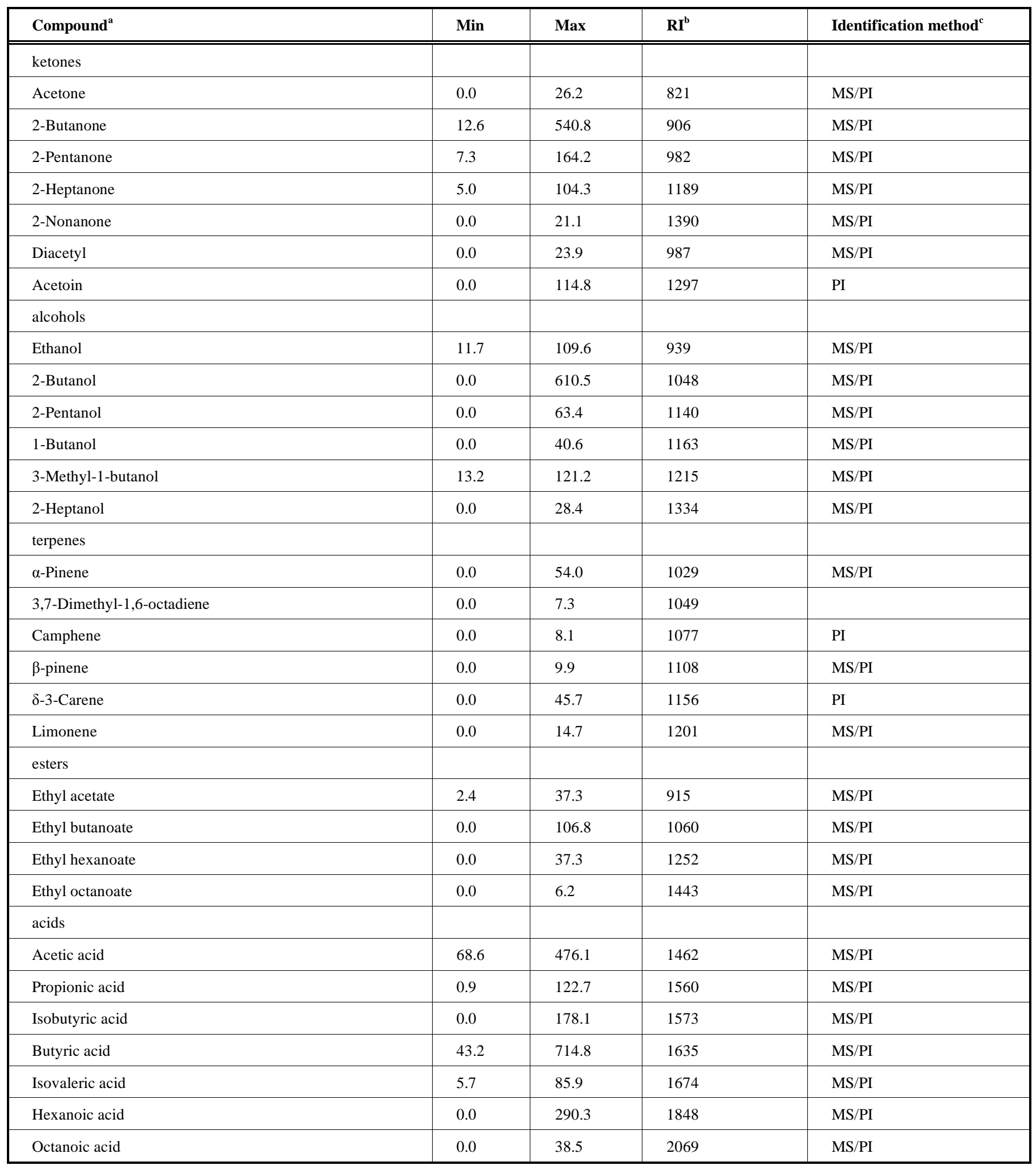

${ }^{\mathrm{a} I d e n t i f i c a t i o n ~ b y ~ c o m p a r i s o n ~ w i t h ~ m a s s ~ s p e c t r a ~ o f ~ W i l e y ~ l i b r a r y ~[24] . ~}$

${ }^{\mathrm{b}} \mathrm{RI}$, retention indices as determined on CP-WAX 52CB column using homologous series of C9-C21 alkanes.

'Identification methods: PI, RI published [27-29]; MS, mass spectra of authentic compounds.

summer period. The analyses of total solids, protein, fat and ash content were performed and the mean values obtained were $65.2,22.7,34.3$, and $3.8 \%$ respectively.
As far as the volatile compounds composition is concerned, the SPME/GC/MS technique was chosen as reference method for the study of the performances of the EGA FT-IR approach. Table $\mathbf{1}$ reports the compounds extracted 
with the ranges of the amounts detected. The most abundant molecules belonged to the chemical classes of ketones, acids, alcohols and esters. Samples showed a certain variability in the volatile compounds composition, and this could be explained by the presence of a hand-crafted production in the manufacture of this type of cheese.

As for the EGA FT-IR technique, the preliminary step of the work was dedicated to the setting up of the best analytical conditions and instrumental parameters for the cheese analysis. The following aspects were considered and optimized: extraction conditions, sample presentation and temperature, number of scans. Fig. (2a) reports the IR spectra obtained with and without the adoption of a concentration step on Tenax. Without the Tenax trap all the headspace ex- tracted by the nitrogen flow reaches the infrared cell and consequently the absorption bands of water are predominant. By using Tenax the volatile compounds in the first step are concentrated in the trap, where water is not retained, whereas in the second step they are desorbed and transferred to the IR gas cell. In order to achieve the best repeatability conditions and maximize the volatile extraction, different types of sample presentation were tested. In particular the same cheese amount of $4 \mathrm{~g}$ was shaped both into only one sphere and into 5 little spheres; the latter preparation, having the highest exchange surface for the volatile compounds, provided the highest bands (Fig. 2b). Another variable that was taken into account was the temperature of the chamber of the desorption unit. Tests were carried out at $60^{\circ} \mathrm{C}, 80^{\circ} \mathrm{C}$ and $100^{\circ} \mathrm{C}$.
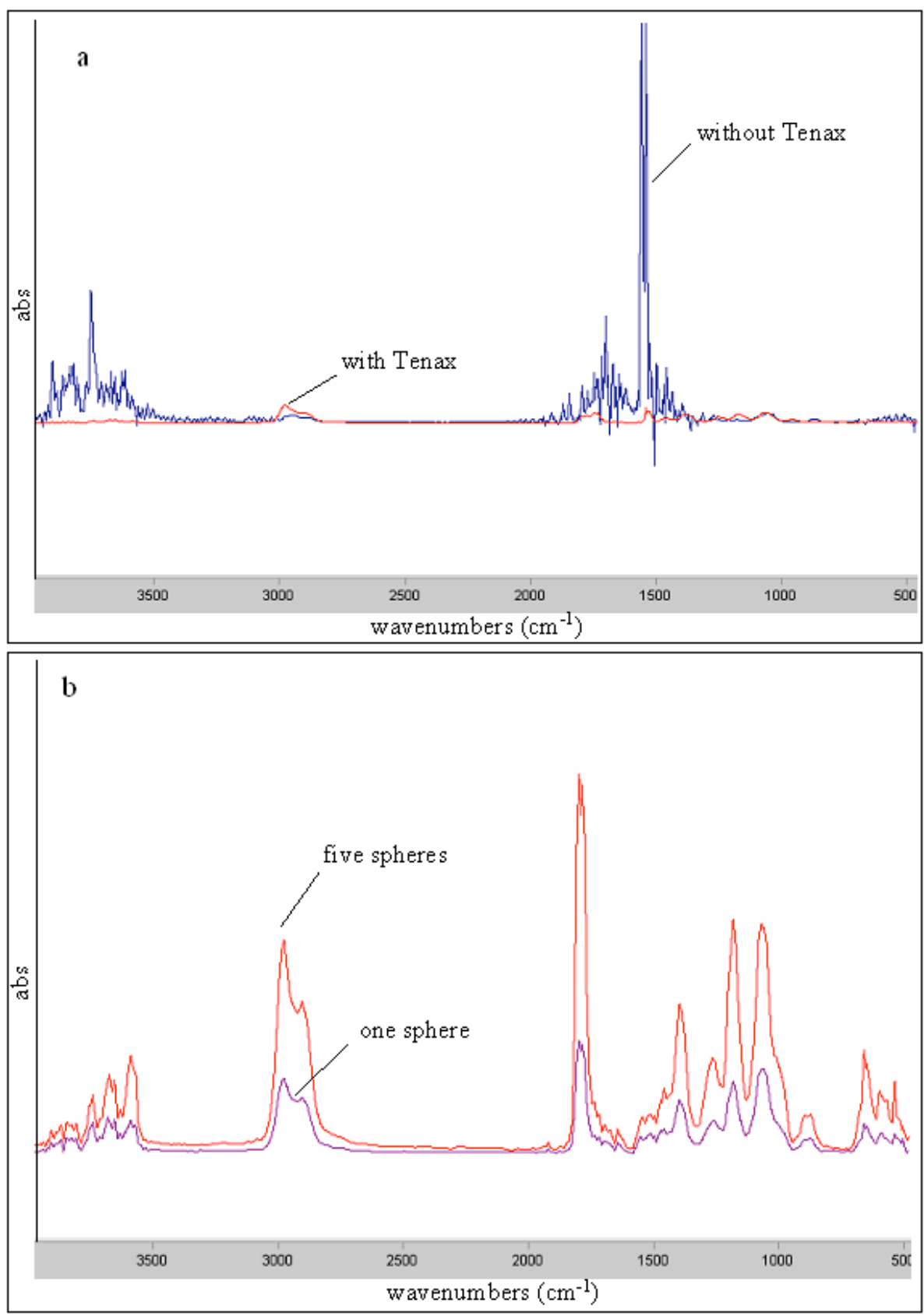

Fig. (2). EGA FT-IR spectra of cheese obtained a) with and without the concentration step on Tenax trap, b) with one sphere and five spheres. 


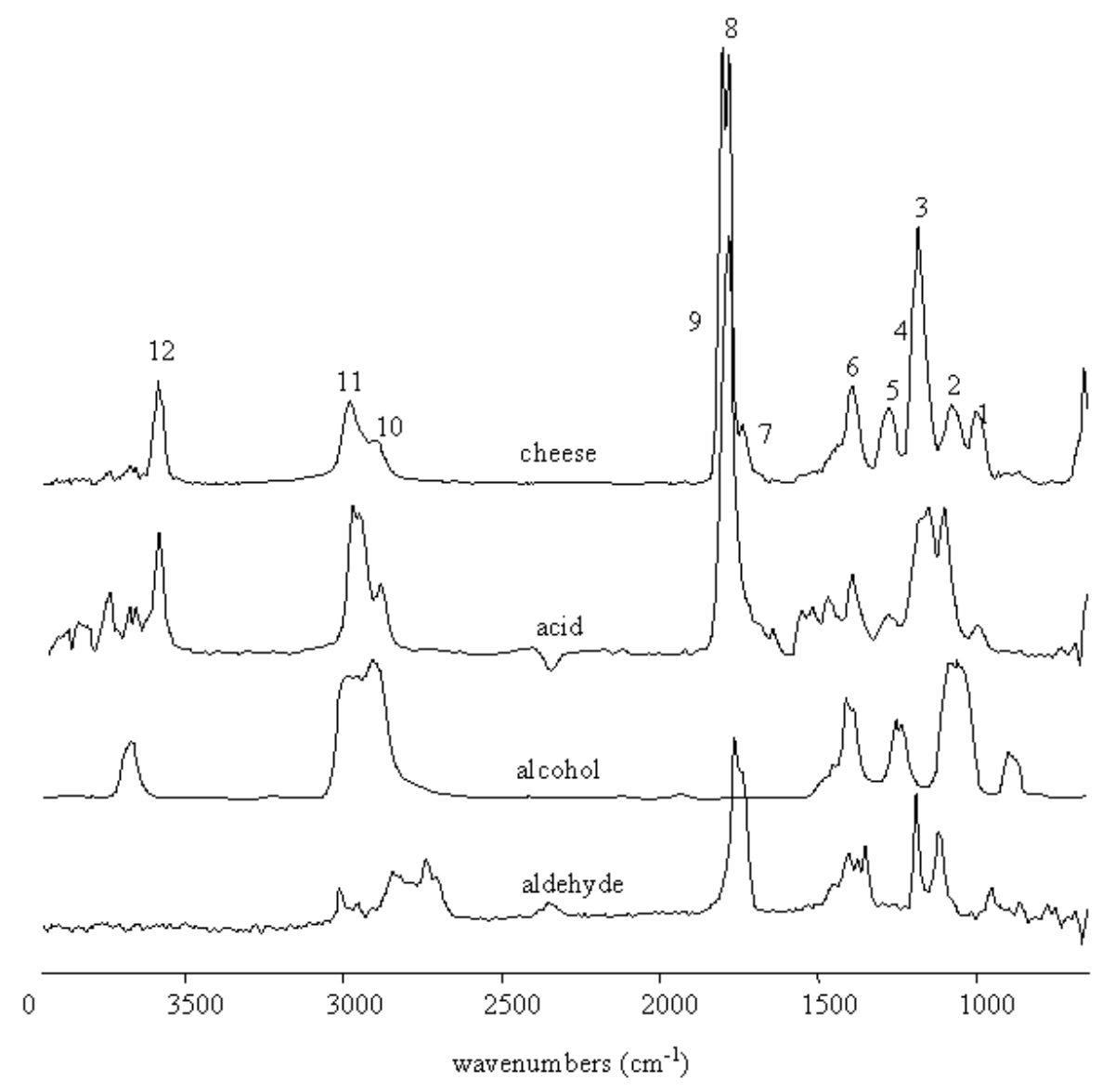

Fig. (3). EGA FT-IR spectra of a Bitto cheese sample, hexanoic acid, ethanol and acetaldehyde.

At the lower temperature a spectrum with weak signal intensities was obtained, whereas at $100^{\circ} \mathrm{C}$ the cheese sample melted. The intermediate temperature of $80^{\circ} \mathrm{C}$ was chosen, since it gave satisfactory signal intensities and it did not cause the sample to melt. At the same time a monitoring of the temperature inside the sample was performed by using a thermal imaging camera, a particular video camera sensitive to infrared radiation and able to detect images or thermographic videos. Using this device with the desorber chamber temperature at $80^{\circ} \mathrm{C}$, a temperature of $39.8^{\circ} \mathrm{C}$ was measured in the sample.

Since the IR spectra are the result of linear combinations of spectra of single molecular compounds, scaled in relation to their concentration, it was necessary to acquire spectra of authentic standards for band assignment by injecting them directly into the Tenax trap by using a gaschromatographic syringe. Fig. (3) shows the stacked spectra of both cheese and the authentic standards: it can be observed the correspondences between the signals arising from the main functional groups present in the standard molecules with some signals obtained from the volatile fraction of cheese. Table 2 reports the main band assignments performed. It is noticeable that, whereas in the condensed phase there are intermolecular interactions mainly due to the hydrogen bonds, in the gas phase, since the molecules do not interact, the effect of the hydrogen bond on vibrational spectrum is absent. In particular the $\mathrm{OH}$ stretching, which, in the condensed phase, usually gives a large band in the range of $3600-3400 \mathrm{~cm}^{-1}$, in the gas phase gives origin to a sharper band, centered at 3340 $\mathrm{cm}^{-1}$; in the same way, the stretching of carbonyls involved in hydrogen bonds are shifted toward 30-50 units higher wavenumbers (e.g. $\mathrm{C}=\mathrm{O}$ of acids, which in condensed phase is at $1740 \mathrm{~cm}^{-1}$, in gas phase is observed at $1783 \mathrm{~cm}^{-1}$ ). From Table 2 and Fig. (3) it is evident that the bands present in the spectrum of Bitto cheese arise from the functional groups of ketones, alcohols, free fatty acids and esters. This was confirmed by the volatile composition obtained by SPME/GC/MS analysis.

Since the EGA FT-IR device used in this research is not a hyphenated instrument and thus it does not perform any separation of the analytes, the comparison with SPME/GC/MS results was made using chemometric techniques in order to extract the useful spectral information. The data matrix was built: it had as many rows as cheese samples (39) and 1779 columns (1768 spectral variables, absorbances at selected wavenumbers, and 11 chemical variables, volatile compounds extracted by SPME). Spectral variables were submitted to Normal Standard Variate method (row autoscaling) for scatter correction, and then chemical variables were added; finally the whole matrix was submitted to column centring. To identify the most informative wavelengths, the spectral data were analysed using the SELECT algorithm [25] of Parvus software [26] which generates a set of decorrelated variables on the basis of their correlation coefficients with the response, which is, in this case, each time a volatile 
Table 2. Main IR Band Assignements

\begin{tabular}{|c|c|c|c|}
\hline No. & Band & Range & Interpretation \\
\hline \hline 1 & 1001 & $950-1010$ & C-C-O asymmetric stretching \\
\hline 2 & 1066 & $1050-1100$ & C-C-O asymmetric stretching \\
\hline 3 & 1177 & $1140-1180$ & C-O stretching \\
\hline 4 & 1197 & $1140-1180$ & C-O stretching \\
\hline 5 & 1275 & $1230-1300$ & O-H stretching \\
\hline 6 & 1393 & $1375-1420$ & C-H bending \\
\hline 7 & 1733 & $1730-1740$ & C=O stretching (aldheydes, ketones) \\
\hline 8 & 1782 & $1770-1800$ & C=O stretching (acids) \\
\hline 9 & 1798 & $1770-1800$ & C=O stretching (esters) \\
\hline 10 & 2901 & $2900-2935$ & C-H symmetric stretching \\
\hline 11 & 2973 & $2940-2980$ & C-H asymmetric stretching \\
\hline 12 & 3582 & $3550-3590$ & O-H stretching \\
\hline
\end{tabular}

Table 3. Results of the Correlation Between Some Volatile Compounds and IR Absorbances

\begin{tabular}{|c|c|c|c|c|}
\hline Compound & Multiple correlation coefficient R & R2 & LOO explained variance \% & LOO mean prediction error \% \\
\hline \hline 2-Butanone & 0.9891 & 0.9784 & 90.9 & 17.8 \\
\hline 2-Pentanone & 0.9912 & 0.9824 & 91.1 & 24.7 \\
\hline Acetoin & 0.9915 & 0.9831 & 93.7 & 10.3 \\
\hline Ethanol & 0.9922 & 0.9844 & 93.6 & 17.7 \\
\hline 2-Butanol & 0.9906 & 0.9814 & 87.3 & 6.2 \\
\hline Acetic acid & 0.9959 & 0.9919 & 96.5 & 25.9 \\
\hline Propionic acid & 0.9942 & 0.9884 & 94.3 & 19.8 \\
\hline Isobutyric acid & 0.9946 & 0.9891 & 95.4 & 12.2 \\
\hline Butyric acid & 0.9921 & 0.9842 & 90.8 & 17.2 \\
\hline Isovaleric acid & 0.9788 & 0.9581 & 81.9 & 19.4 \\
\hline Hexanoic acid & 0.9870 & 0.9743 & 86.3 & \\
\hline
\end{tabular}

compound extracted by SPME. Then, the decorrelated variables were used as independent variables in a Ordinary Least Squares Regression (OLS) against the response. The regression results were validated by Leave-One-Out cross validation (LOO). Satisfactory correlations were provided only by the most abundant volatile compounds belonging to the classes of ketones, alcohols and acids (Table $\mathbf{3}$ ), whereas no correlation was found between spectral information and terpenes.

\section{CONCLUSIONS}

The research represents a preliminary investigation of the application of a new analytical approach for the volatile compounds evaluation. The system tested appeared to be appealing due to its robustness, easy to use and minimal maintenance. Some aspects of the analytical conditions still need to be improved, in particular as regards repeatability and sensitivity. With this in mind the standardization of the sample presentation should be improved and a higher sensitivity could be achieved by using a FT-IR spectrometer equipped with a Mercury Cadmium Telluride (MCT) detector. Nevertheless, the results obtained are promising for a possible development and application of EGA FT-IR in the evaluation of volatile fraction of foods.

\section{ABBREVIATIONS \\ DTGS $=$ Deuterated Triglycine Sulfate \\ EGA $=$ Evolved Gas Analysis}




$$
\begin{array}{ll}
\text { FT-IR } & =\text { Fourier-transform infrared spectroscopy } \\
\text { GC } & =\text { Gaschromatography } \\
\text { LOO } & =\text { Leave-One-Out cross validation } \\
\text { MCT } & =\text { Mercury Cadmium Telluride } \\
\text { MS } & =\text { Mass Spectrometry } \\
\text { OLS } & =\text { Ordinary Least Squares Regression } \\
\text { PDO } & =\text { Protected Designation of Origin } \\
\text { SPME } & =\text { Solid Phase Microextraction } \\
\text { REFERENCES }
\end{array}
$$

\section{REFERENCES}

[1] Mariaca R, Bosset JO. Instrumental analysis of volatile (flavour) compounds in milk and dairy products. Lait 1997; 77: 13-40.

[2] Le Quéré J-L, Pierre A, Riaublanc A, Demaiziéres D. Characterization of aroma compounds in the volatile fraction of soft goat cheese during ripening. Lait 1998; 78: 279-90.

[3] Carbonell M, Nuñez M, Fernández-García E. Evolution of the volatile components of ewe raw milk La Serena cheese during ripening. Correlation with flavour characteristics. Lait 2002; 82: 68398.

[4] Buchin S, Martin B, Dupont D, Bornard A, Achilleos C. Influence of the composition of Alpine highland pasture on the chemical, rheological and sensory properties of cheese. J Dairy Res 1999; 66: 579-88.

[5] Bugaud C, Buchin S, Hauwuy A, Coulon, JB. Relationships between flavour and chemical composition of Abondance cheese derived from different types of pastures. Lait 2001; 81: 757-73.

[6] De Noni I, Battelli G. Terpenes and fatty acid profiles of milk fat and "Bitto" cheese as affected by transhumance of cows on different mountain pastures. Food Chem 2008; 109: 299-309.

[7] Kim GY, Lee JH, Min DB. Study of light-induced volatile compounds in goat's milk cheese. J Agric Food Chem 2003; 51: 14059.

[8] Verdier-Metz I, Coulon JB, Pradel P, Viallon C, Albouy H, Berdagué JL. Effect of the botanical composition of hay and casein genetic variants on the chemical and sensory characteristics of ripened Saint-Nectaire type cheeses. Lait 2000; 80: 361-70.

[9] Cosio MS, Mannino S, Buratti S. Electrochemical sensor detecting free sulfhydryl groups: evaluation of milk heat treatment. J Dairy Sci 2000; 83: 1933-38.

[10] Pillonel L, Ampuero S, Tabacchi R, Bosset JO. Analytical methods for the determination of the geographic origin of Emmenthal cheese: volatile compounds by GC/MS-FID and electronic nose. Eur Food Res Technol 2003; 216: 179-83.

[11] Andersen SK, Hansen PW, Andersen HV. Vibrational Spectroscopy in the analysis of dairy products and wine. In: Chalmers JM and Griffiths PR, Eds. Handbook of Vibrational Spectroscopy. Chichester, UK: John Wiley \& Sons Ltd 2002; vol. 5 pp. 3672-82.

[12] International Standard ISO 9622:1999. Whole milk - Determination of milkfat, protein and lactose content - Guidance on the operation of mid-infrared instruments., International Organization for Standardization 1999, Geneva.

[13] Visser T. FT-IR detection in gas chromatography. Trend Anal Chem 2002; 21 (9+10): 627-36.

[14] Materazzi S, Gentili A, Curini R. Applications of evolved gas analysis. Part 1: EGA by infrared spectroscopy. Talanta 2006; 68: 489-96.

[15] Hellgeth JW. Thermal analysis-IR methods. In: Chalmers JM and Griffiths PR, Eds. Handbook of Vibrational Spectroscopy. Chichester, UK: John Wiley \& Sons Ltd 2002; vol. 2 pp. 1605-26.

[16] Materazzi S, De Angelis Curtis S, Sagone F, et al. Thermal analysis and food quality. The possibility to qualify the pasta processing. J Therm Anal Calorim 2005; 80: 465-67.

[17] Chalmers JM, Everall NJ. Qualitative and quantitative analysis of plastics, polymers and rubbers by vibrational spectroscopy. In: Everall NJ, Chalmers JM and Griffiths PR, Eds. Vibrational Spectroscopy of Polymers: Principles and Practice. Chichester, UK: John Wiley \& Sons Ltd 2007; p. 43.

[18] Perren R, Künzli R, Escher F. Gas and Thermal Analysis in optimizing roasting processes of foods. Chimia 2002; 56 (6): 265-69.

[19] International Standard ISO 5534 / IDF 4:2004. Cheese and processed cheese - Determination of the total solids content (Reference method). Belgium: International Dairy Federation.

[20] International Standard ISO 1735 / IDF 5:2004. Cheese and processed cheese products - Determination of fat content - Gravimetric method (Reference method). Belgium: International Dairy Federation.

[21] AOAC. Official Methods of Analysis. 17th ed. Gaithersburg, MD: Association of Official Analytical Chemists International 2000; vol 2.

[22] International Standard ISO 8968-3 / IDF 20-3:2004. Milk - Determination of nitrogen content - Part 3: Block-digestion method (Semi-micro rapid routine method). Belgium: International Dairy Federation.

[23] Povolo M, Contarini G, Mele M, Secchiari P. Study on the influence of pasture on volatile fraction of ewes' dairy products by Solid-Phase Microextraction and gas chromatography-mass spectrometry. J Dairy Sci 2007; 90: 556-69.

[24] McLafferty F, Stauffer D. Wiley registry of mass spectral data. New York, NY: Wiley 1988.

[25] Kowalski BR, Bender, CF. An orthogonal feature selection method. Pattern Recogn 1976; 8(1): 1-4.

[26] Forina M, Lanteri S, Armanino C, Casolino C, Casale M. VPARVUS 2007. An extendable package of programs for explorative data analysis, classification and regression analysis. Dipartimento di Chimica e Tecnologie Farmaceutiche ed Alimentari, University of Genova. Free available at http://www.parvus.unige.it

[27] Jennings W, Shibamoto T. Qualitative analysis of flavour volatiles by glass capillary gas chromatography. London, UK: Academic Press 1980.

[28] Acree T, Arn H. Flavornet and human odor space. http://www.flavornet.org 2004 (accessed February 2009).

[29] El-Sayed AM. The Pherobase: Database of Insect Pheromones and Semiochemicals. http://www.pherobase.com 2008 (accessed February 2009) 